\title{
Performance of different management practices on tomato fruit borer (Helicoverpa armigera Hubner) abundance and infestation
}

\author{
M. Dey, S. Das, M. M. Kamal ${ }^{*}$ and R. Sarkar ${ }^{1}$ \\ Agrotechnology Discipline, Khulna University, Bangladesh and ${ }^{1}$ Department of Agricultural Extension (DAE), \\ Bangladesh, *E-mail: mostofaku@gmail.com
}

\begin{abstract}
A research work based on eco-friendly management practices was undertaken at Agro-technology research field, Khulna University containing five treatments viz. Neem (Azadirachta indicia A. Juss.), Netting, Pheromone, Mahogoni (Swietenia mahagoni L.) and untreated control in RCBD with four replications aiming to evaluate their efficacy against tomato fruit borer, Helicoverpa armigera Hubner infestation. Data were taken on tomato fruit infestation (\%), number of holes and number of larvae per infested fruit. All eco-friendly management practices had remarkable action against the tomato fruit borer, of which Netting claimed the highest position to protect tomato fruit borer infestation compared to other management practices whereas the highest insect infestation took place in untreated control. So, to infer, Netting is very promising and efficient tool in controlling tomato fruit borer for safe and quality tomato production.
\end{abstract}

Keywords: Tomato fruit borer, Infestation and Eco-friendly management practices

\section{Introduction}

Tomato (Lycopersicon esculentum Mill.) is one of the most important and popular vegetables in Bangladesh as well as in the world. It ranks third position in the world's vegetable production, next to potato and sweet potato. It is a cheap source of vitamin- $C$ and minerals. Tomato covers about 63000 acre of the total cultivable area of all vegetables in Bangladesh and its yield was 255000 metric tons during the crop year 2011-12 where per acre yield was $4035 \mathrm{~kg}$ per acre whereas, in south western region of Bangladesh especially in Khulna tomato yield is 9474 metric tons in 2090 acre lands (BBS, 2012) that is low as per expectation.

There are many reasons for low production of tomato in Bangladesh of which insect pest infestation is the most concerning one for the tomato growers all over the world. Tomatoes are naturally found to be subjected to the attack by a large number of insect pests from the time plants first emerged in the seed bed until harvest. Of the various insect pests, fruit borer, Helicoverpa armigera is the most damaging insect pest of tomato along with other vegetable crops, including eggplants, okra and peppers. The insect is an economically significant pest distributed throughout the world, attacking many crops and tropical solanaceous vegetables especially tomato (Wagh et al., 2012).

Both adult and young are responsible for the damage of tomato where larvae largely damage the host plant fruit as they feed on the seeds and flesh, and moth damage the host plant foliage mainly by ovipositional activities. Larval damage, especially the holes, larvae make, when they emerge from the fruit bores, can provide a pathway for disease-causing micro-organisms to enter the plant resulting in the development of diseases as well (Shah et al., 2013). Larval damage can cause fruits to fall prematurely, rendering them unmarketable and unfit for human consumption. Tomato Fruit Borer damage can also be responsible for decreasing the seed viability compared to undamaged fruit (Karabhantanal and Awaknavar, 2013).

To control the borer, many preventive measures have been reported across the world. Among these, chemical insecticides can be used for effective control but they have extreme adverse effects on environment and consumers. Moreover, continuous use of chemical insecticides develops cross and multiple resistant strains in many important insect species (Geiger et al., 2010) including this fruit borer. However, to avoid the hazardous effect on ecology and ultimate consumers, now-a- days different time demanded eco-friendly control tactics viz. botanicals, microbes, pheromone, netting, etc. are extensively being used over world. Among various botanicals, Neem (Azadirachta indicia A. Juss.) and Mahogani (Swietenia mahagoni L.) occupy higher position in crop protection for its high insecticidal behavior against 
different harmful insect pest (Rayhan et al.,2014). Likewise, another widely recognized eco-friendly management tool, sex pheromones is immensely exploited in integrated pest management program due to being relatively easy to use and less expensive, species specific, and environmentally benign (Cork et al., 2003). Insect netting is also very effective in reducing moths and caterpillars on high-value vegetables and usually a 50-mesh white fabric worked very well to block a number of major vegetable insect pests from reaching the crop (Martin et al., 2006).

But the fact is that researches on the effectiveness of various eco-friendly insect exclusion techniques for sustainable safe vegetable production in Bangladesh are not as adequate as expected. That is why, the experiment was undertaken aiming to control the tomato fruit borer (TFB) infestation in ecological safe way and simultaneously to evaluate the best performing management practice among the used ones.

\section{Materials and Methods}

The experiments were carried out in Agro-technology research field, Khulna University during the time period from November, 2014 to March, 2015 to record the reliable data in order for assessing the comparative performance of eco-friendly management tools against Tomato Fruit Borer (TFB) infestation in ex situ condition.

\section{Treatments}

a. Neem oil at rate of $2 \%$ at 10 days interval

b. Mahogani oil at rate of $2 \%$ at 10 days interval

c. Pheromone trap where lure was replaced by fresh ones at an interval of 30 days

d. Netting (Insect proof net) and

e. Untreated control

The field experiment was laid out in Randomized Block Design (RBD) maintaining 5 treatments including untreated control, each replicated 4 times. The size of a unit plot was $20.00 \mathrm{~m} \times 10.00 \mathrm{~m}$. Distance of 1.00 $\mathrm{m}$ between blocks and $0.5 \mathrm{~m}$ between the plots was maintained to facilitate different intercultural operations.

\section{Data collection parameters}

Estimation of infested fruit percentage: Number of infested fruits was counted from total harvested fruits per plot and then its percentage was calculated as:

Infested fruit percentage $=\frac{\text { Number of infested fruits }(\mathrm{IF})}{\text { Number of total fruits }(\mathrm{TF})} \times 100$

Number of holes per infested fruit: The infested fruits were collected from each tomato plant during different fruiting stage (early, mid and late stage) and thereafter, number of holes per infested fruit was counted visually.

Mean number of holes per infested fruit $=\frac{\text { Total number of } \frac{\text { holes }}{\text { fruit }}}{\text { Total number of infestated fruits }}$

Number of larvae (borer) per fruit: Firstly the infested fruits were collected from each plot. Secondly number of larvae per infested fruit was visually estimated through dissection and finally their average value was estimated by the formula as follows:

Mean number of borer per fruit $=\frac{\text { Total number of borers per fruit }}{\text { Total number of infested fruit per plot }}$ 


\section{Data analysis}

The recorded data were analyzed statistically for ANOVA (Analysis of Variance) with the help of computer package program MSTAT-C where the mean differences were adjudged by Duncan's New Multiple Range Test (DMRT) (Gomez and Gomez, 1984).

\section{Results and Discussion}

The ex situ relative performance of some eco-friendly management tools was appraised against the Tomato Fruit Borer (TFB) Helicoverpa armigera, based on the results obtained from the experiment, were precisely highlighted under the following heads:

\section{Impact of management practices on tomato fruit infestation}

The eco-friendly management practices showed statistical significant difference from untreated control $(p<0.05)$ in protecting tomato from $\mathrm{H}$. armigera infestation (Table 1 ). In early fruiting stage, the infested fruit percentage was the lowest $(0 \%)$ in Netting, preceded by Pheromone $(6.89 \%)$ and the highest $(13.82 \%)$ was recorded in control followed by Mahogani (8.82\%).

Table 1. Impact of management practices on tomato fruit infestation (\%) at different fruiting stage

\begin{tabular}{l|c|c|c}
\hline Management & \multicolumn{3}{c}{ \% fruit infestation } \\
\cline { 2 - 4 } Practices & Early Stage & Mid Stage & Late Stage \\
\hline Neem oil & $7.12 \mathrm{~b}$ & $7.30 \mathrm{c}$ & $4.97 \mathrm{c}$ \\
Netting & $0.00 \mathrm{~d}$ & $0.00 \mathrm{~d}$ & $0.00 \mathrm{~d}$ \\
Pheromone & $6.89 \mathrm{c}$ & $12.44 \mathrm{~b}$ & $9.07 \mathrm{~b}$ \\
Mahagoni oil & $8.82 \mathrm{~b}$ & $12.03 \mathrm{~b}$ & $8.53 \mathrm{~b}$ \\
Control & $13.82 \mathrm{a}$ & $23.06 \mathrm{a}$ & $28.73 \mathrm{a}$ \\
\hline LS & $\star$ & $*$ & $*$ \\
Mean & 7.33 & 10.97 & 10.26 \\
SE \pm & 2.21 & 3.76 & 4.89 \\
\hline
\end{tabular}

LS = Level of significance

SE $=$ Standard error

* $=$ Significant at $5 \%$ level

Within the table different letter (s) in same column indicate significance difference by DMRT

In mid fruiting stage, the infestation was the highest (23.06\%) in control followed by Mahogani (12.44\%) and the lowest $(0 \%)$ was in Netting preceded by Neem $(7.3 \%)$. Finally in late fruiting stage, the fruit infestation was estimated the highest $(28.73 \%)$ in Control, followed by Pheromone $(9.07 \%)$ and the lowest was in Netting (0\%) preceded by Neem (4.97\%). So, it was apparent that among the five different management practices, there was no fruit infestation in Netting and very few in Neemoil treated plants in all fruiting stages.

Netting offered $90 \%$ reduction of tomato fruit infestation in the field condition (Majumdar and Powell, 2011) which was more or less similar to the present study. Besides, 50 mesh insect netting significantly protect the tomato fruit worm $(H$. Zea) infestation and Beet army worm (Spodoptera exigua) compared to ex situ condition and effectiveness was $82-100 \%$. The armyworm and tomato fruit worm caterpillar numbers reduced $98-100 \%$ under net house (Majumdar et al., 2015) that is pretty similar to the present findings. Different earlier literature showed the effectiveness of botanicals against different insect species. The effect of different botanicals extracts i.e. Neem seed extract (2.5\%), Turmeric extract (5\%), Henge extract (1.25\%), Garlic extract (5\%) and insecticide, emamectin benzoate (0.07\%) were very effective in controlling $\mathrm{H}$. armigera infestation to tomato where maximum yield $(7540 \mathrm{~kg} / \mathrm{ha})$ was recorded in Neem seed extract $(2.5 \%)$ and percent infestation of larvae of tomato fruit worm was minimum (0.40) in emamectin benzoate whereas maximum in control plot. So in terms of environment healthiness Neem seed extract is the most promising insecticide for the effective management of tomato fruit worm larvae 
(Shahet al., 2013). Moreover, sex pheromone trap was very effective to control lepidopterors fruit borer moth infestation to different vegetable crops (Prasannakumar et al., 2013). In the study, Neem, Mahogani and pheromone were also very efficacious in controlling tomato fruit borer infestation but netting surpassed all. In early fruiting stage, Neem and Mahogani were statistically similar in their functioning and, in mid and late fruiting stage Mahogani did not show any significant difference with pheromone whereas netting was significantly different from others.

\section{Effect of different management practices on the holes of infested fruit}

Different ecological safe management tools used in this experiment were statistically significant $(p<0.05)$ in preventing tomato fruit infestation (Fig 1). At early fruiting stage, the number of the holes was the lowest in Netting (0.00), preceded by Neem (1.00) and the highest was recorded in control (1.88) followed by Pheromone (1.66) whereas, in mid fruiting stage, the holes in the infested fruits was the highest in control (3.77) followed by Mahogani (2.11) and the lowest in Netting (0) preceded by Neem (1.55) and finally at late fruiting stage, the highest number of the holes was estimated in Control (5.00), followed by Mahogani (2.55) and the lowest was in netting (0) preceded by Neem (1.88). Of the five management practices, no hole was found in tomato fruits because no insect could enter into the fruit. In fact, the net with finest pore diameter made a strong physical barrier to pests that literally disrupted their feeding on tomato fruits (Martin et al. 2013), resulting in no hole on tomato. Side by side, other three ecofriendly management tools also effectively decreased the fruit damage by the pest but their efficacy against fruit damage was not statistically different (Fig. 1).

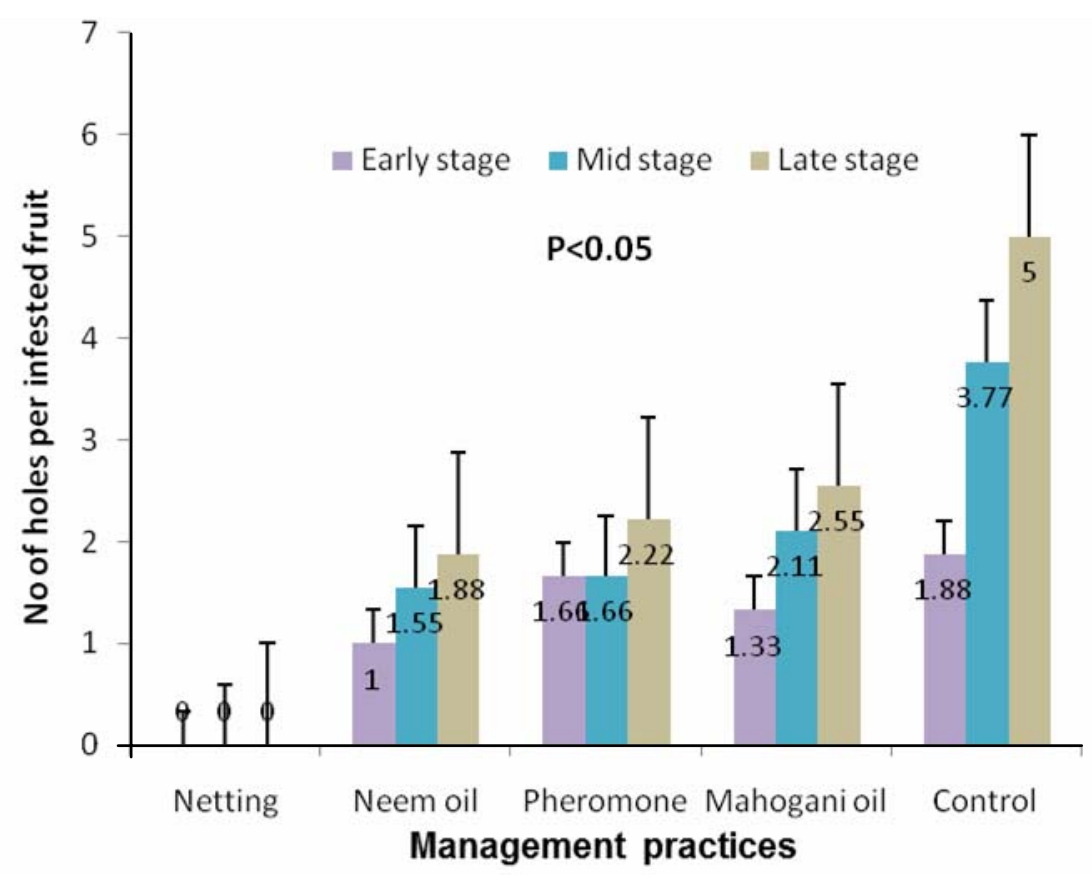

Fig. 1. Number of holes per infested fruit at different fruiting stages under different management practices

\section{Estimation of larval number in infested fruit under different management practices}

From the experiment, it was noticed that at early fruiting stage, the number of the larvae (borer) was the lowest in Netting (0.00), preceded by Neem (1.00) and the highest was recorded in control (1.55) followed by Mahogani ( 1.5) whereas, at mid fruiting stage, the number of the larvae (borer) was the highest in control (1.73) followed by Mahogani (1.56) and the lowest in Netting (0.00) preceded by Pheromone (1.55) and finally at late fruiting stage, the highest incidence of the number of the borer (larvae) was estimated in Control (1.89), followed by Mahogani (1.72) and the lowest was in netting (0) preceded by Neem (1.02). 
As was seen from the table, it was very distinct that there were statistical significant variation $(p<0.05)$ among five management practices of which netting was most efficient tool to protect the tomato fruit from larval infestation and this was due to no entrance of adult moth in the netted tomato plots (Fig 2). Basically, the very fine meshes of the net hindered the insects to infest the fruits (Martin et al., 2006). On the other hand, among other management options, pheromone and Neem oil offered the statistically similar result even though they were numerically different.

In this experiment the botanicals also efficiently protected the larval infestation to fruit at different fruiting stages. In addition, pheromone trap at rate of 65 numbers per hectare provided substantial defense in eggplant shoot damage (58.39\%) and fruit damage (38.17\%) over control (Dutta et al., 2011). In the study pheromone also offered the better control over larval infestation.

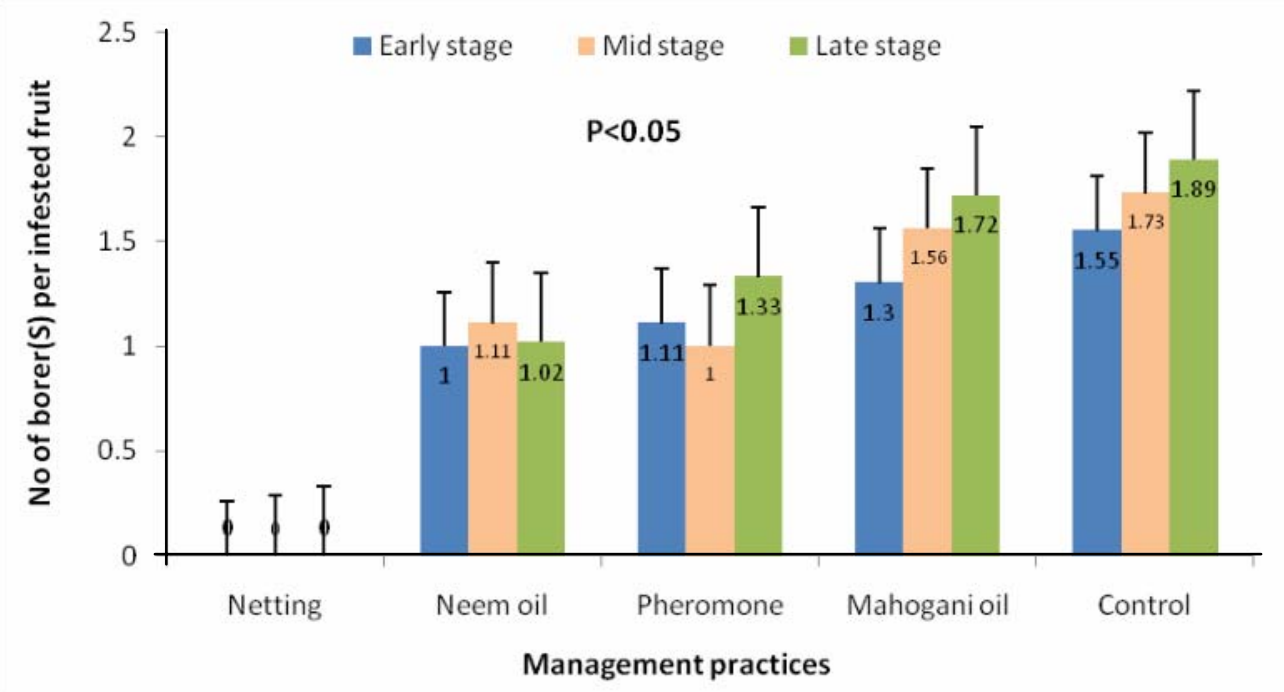

Fig. 2. Number of larvae (borers) per infested fruit at different fruiting stages under different management practices

\section{Conclusion}

From the result, it can be concluded that eco-friendly management tools viz. natural plant products like Neem oil and Mahogani oil as well as mechanical tools like Pheromone trap and Netting played tremendous role to prevent the severe damage of tomato caused by Tomato Fruit Borer in field, resulting in its' higher production in cost effective and safe way, of which Netting were proved to be highly effective against Tomato Fruit Borer infestation. So, growers could be motivated to apply Netting for efficient management of TFB for better yield.

\section{References}

Bangladesh Bureau of Statistics (BBS). 2012. Yearbook of agricultural statistics: Area and production of tomato by region. Statistics and informatics division. Ministry of planning. Government of the people's republic of Bangladesh.

Cork, A., Alam, S.N., Rouf, F.M.A. and Talekar, N.S. 2003. Female sex pheromone of brinjal fruit and shoot borer, Leucinodes orbonalis (Lepidoptera: Pyralidae): trap optimization and application in IPM trials. Bull. Ent. Res. 93(2): 107-113.

Dutta, P., Singha, A.K., Das, P. and Kalita, S. 2011.Management of brinjal fruit and shoot borer, Leucinodes orbanalis Guenee in agro-ecological condition of West Tripura. Schol. J. agric. Sci.. 1(2): 16-19.

Geiger, F., Bengtsson, J., Berendse, F., Weisser, W.W., Emmerson, M., Morales, M.B., Ceryngier, P., Liira, J., Tscharntke, T., Winqvist, C. and Eggers, S. 2010. Persistent negative effects of pesticides on biodiversity and biological control potential on European farmland. Basic and Applied Ecology. 11(2): 97-105.

Gomez, K.A. and A.A. Gomez. 1984. Statistical Procedures for Agric. Res. $2^{\text {nd }}$ Edition, John Wiley and Sons, New York, USA. pp. 97-111. 
Karabhantanal, S. and J. Awaknavar. 2013. Bio intensive approach for the management of tomato fruit borer, Helicoverpa armigera (Hubner). Pest Manag. Hort. Ecosys. 18: 135-138.

Majumdar, A. and M. Powell. 2011. Net House Vegetable Production: Pest Management Successes and Challenges. J. Nat. Assoc. Country Agric. Agents. 4(1): 355-363. http://www.nacaa.com/journal/index.php?jid=87.

Majumdar, A., Chambliss, A., Mastin, W. and Carpenter, S. 2015. High Tunnel Pest Exclusion System: Laboratory and Field Experiences. J. Nat. Assoc. Country Agric. Agents.. 8(1). http://www.nacaa.com/journal/index.php?jid=487.

Martin, T., Palix, R., Kamal, A., Delétré, E., Bonafos, R., Simon. S. and Ngouajio, M. 2013. A repellent net as a new technology to protect cabbage crops. J. econ. entomol.106: 1699-1706.

Martin, T., Assogba-Komlan, F., Houndete, T., Hougard, J.M. and Chandre, F. 2006. Efficacy of mosquito netting for sustainable small holders' cabbage production in Africa.J. econ. entomol. 99: 450-454.

Prasannakumar, N., Chakravarthy, A. and Kumar, L.V. 2013. Relationship between pheromone trap catches and field damage of selected lepidopterous pests on vegetable crops. Pest Manag. Hort. Ecosys.15: 63-67.

Rayhan, M.Z., Das, S., Sarkar, R., Adhikary, S.K., Tania, S.N., Islam, M.M. and Rabbani, M.G. 2014. Bio-efficacy of neem, mahogoni and their mixture to protect seed damage and seed weight loss by rice weevil in storage. J. Biodiversity and Environ. Sci. 5: 582-587.

Shah, J., Inayatullah, M., Sohail, K., Shah, S., Iqbal, T. and Usman, M. 2013. Efficacy of botanical extracts and a chemical pesticide against tomato fruit worm, Helicoverpa armigera (Lepidoptera: Noctuidae). Sarhad J. Agric. 29: 93-96.

Wagh, S., Patil, P., Lad, S. and Patil, S. 2012. Eco-friendly management of tomato pests. Int. J. Plant Protec. 5: 45-48. 